\title{
Editorial Statistics and Best Reviewers Award for 2019
}

\author{
Toyoaki Murohara, MD, $\mathrm{PhD}$
}

Dear Colleagues,

On behalf of the Circulation Journal, I am pleased to announce the editorial statistics for 2019, and the recipients of the Best Reviewers Awards for 2019.

\section{Editorial statistics for 2019}

As shown in Figure 1, we received 1,211 manuscripts in 2019, for publication in the Journal, including 946 original papers ( 838 clinical and 108 experimental), 12 invited review articles, 39 invited editorials, 25 rapid
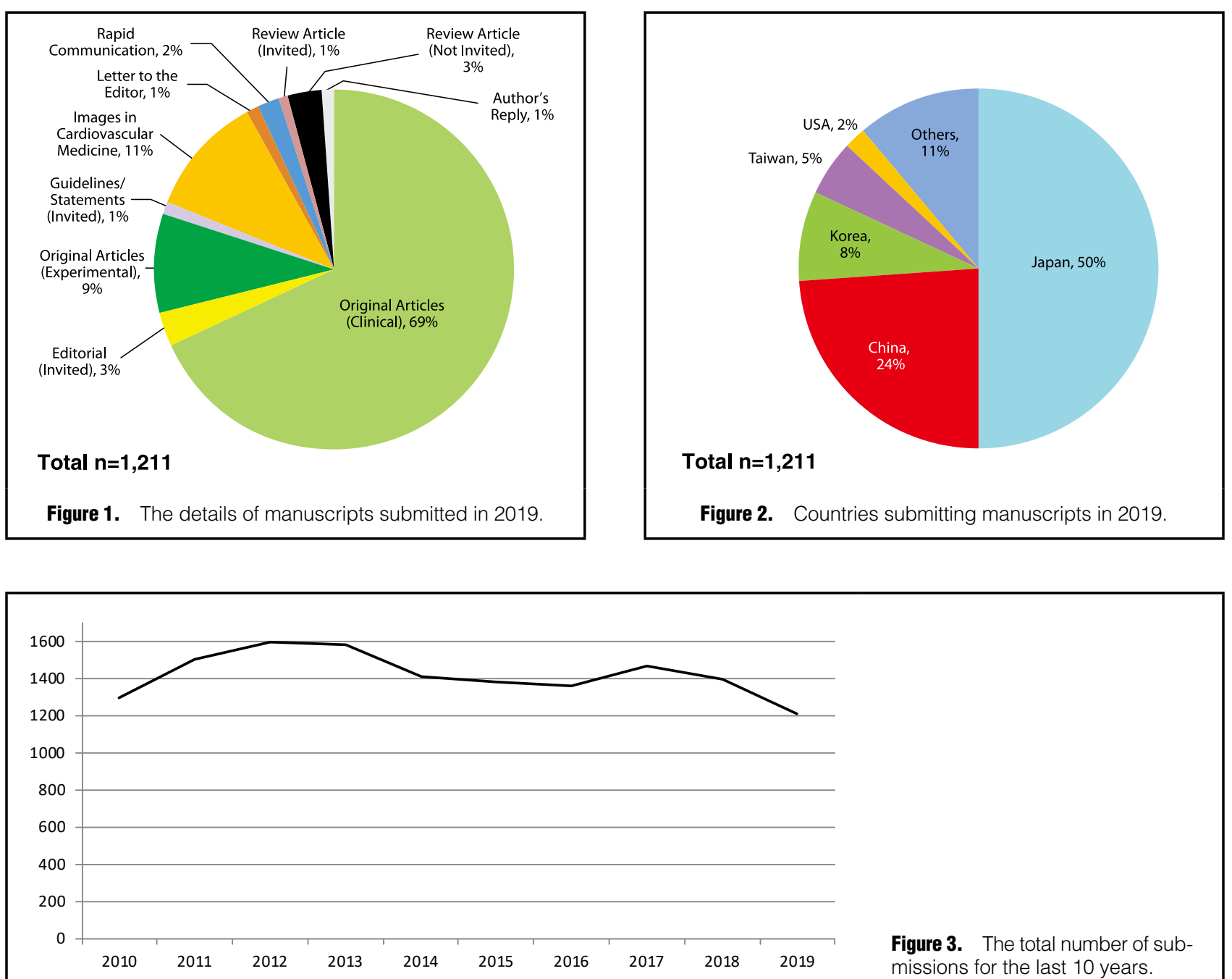

Figure 3. The total number of submissions for the last 10 years.

J-STAGE Advance Publication released online January 18, 2020

Department of Cardiology, Nagoya University Graduate School of Medicine, Nagoya, Japan

Mailing address: Toyoaki Murohara, MD, PhD, Department of Cardiology, Nagoya University Graduate School of Medicine, 65

Tsurumai, Showa-ku, Nagoya 466-8550, Japan. E-mail: murohara@med.nagoya-u.ac.jp

ISSN-1346-9843 All rights are reserved to the Japanese Circulation Society. For permissions, please e-mail: cj@j-circ.or.jp 


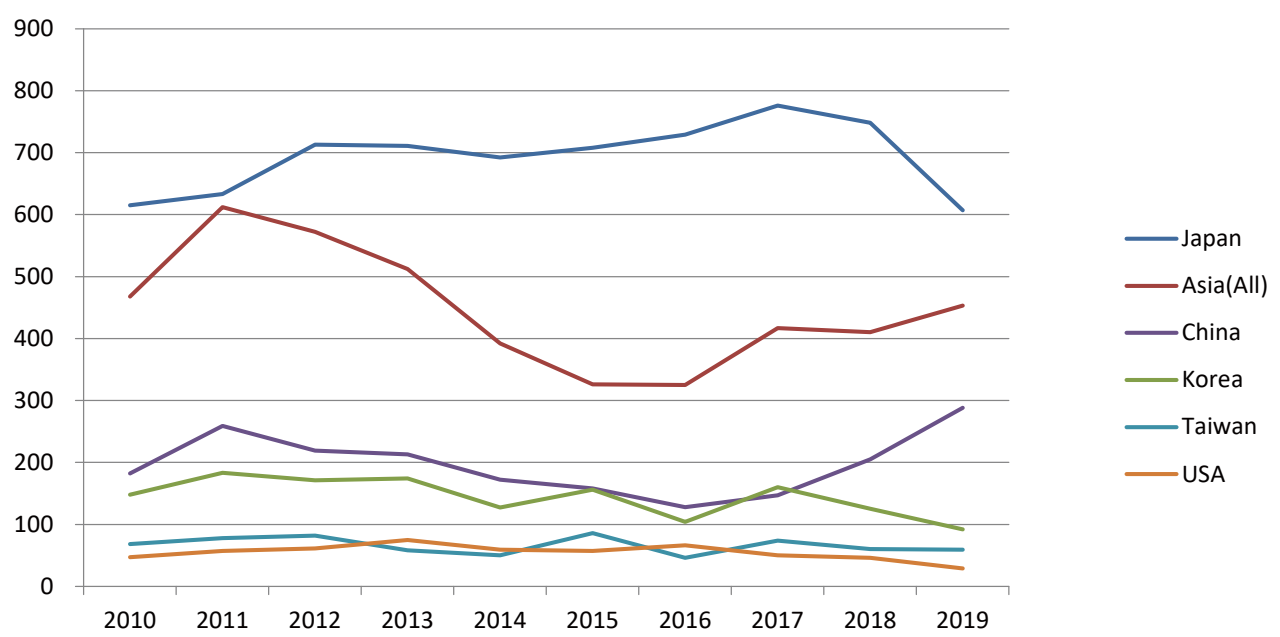

Figure 4. The number of submissions for the last 10 years in top 5 countries. Asia (All): all Asian countries except Japan.

communications, and 130 images in cardiovascular medicine. Approximately half were submitted from Japan, followed by China, Korea, Taiwan, and USA (Figure 2). For the last 10 years, the number of submissions has been steadily increasing even after we terminated publication of case reports in October 2008 (Figure 3). The abovementioned 5 countries have remained the top 5 countries in terms of paper submissions over that period (Figure 4). The acceptance rate for original manuscripts in 2019 was approximately $\mathbf{2 4 . 9} \%$.

\section{Best Reviewers Awards for 2019}

In 2019, a total of 961 reviewers kindly reviewed the manuscripts submitted. In appreciation of their valuable contributions, we have selected the 20 Best Reviewers of the Year 2019 as follows:

\section{Hirohiko Ando, MD}

(Aichi Medical University, Aichi)

Number of reviews: 19

RPS: 124.0

Previous awards: 2017

\section{Hiroshi Asanuma, MD}

(Meiji University of Integrative Medicine, Kyoto)

Number of reviews: 15

RPS: 90.0

Previous awards: 2009, 2010, 2011, 2012, 2013, 2014 , 2015, 2016, 2017, 2018

\section{Shinsuke Miyazaki, MD}

(Faculty of Medical Sciences, University of Fukui, Fukui) Number of reviews: 14

RPS: 84.0

Previous awards: 2015, 2017, 2018

\section{Shin Ito, MD}

(National Cerebral and Cardiovascular Center, Osaka)

Number of reviews: 15

RPS: 81.0

Previous awards: 2017, 2018

\section{Hideki Ishii, MD}

(Nagoya University Graduate School of Medicine, Aichi) Number of reviews: 15

RPS: 110.0

Previous awards: 2008, 2011, 2012, 2015, 2016, 2017 ,

\section{Osamu Tsukamoto, MD}

(Osaka University Graduate School of Medicine, Osaka) Number of reviews: 15

RPS: 87.0

Previous awards: 2012, 2013, 2014, 2015, 2016, 2017 , 2018

\section{Kenichi Tsujita, MD}

(Kumamoto University, Kumamoto)

Number of reviews: 15

RPS: 81.2

Previous awards: 2017

\section{Naohiko Takahashi, MD}

(Oita University, Oita)

Number of reviews: 13

RPS: 75.0

Previous awards: 2011, 2012, 2013, 2014, 2016, 2017, 
Shoji Sanada, MD

(Osaka City University, Osaka)

Number of reviews: 13

RPS: 72.0

Previous awards: 2008, 2009, 2010, 2011, 2012, 2013, 2014, 2015, 2016, 2017, 2018

\section{Yoshihiro Seo, MD}

(Nagoya City University Graduate School of Medical Sciences, Aichi)

Number of reviews: 10

RPS: 57.0

Previous awards: 2012, 2015, 2016, 2017, 2018

\section{Akiomi Yoshihisa, MD}

(Fukushima Medical University, Fukushima)

Number of reviews: 8

RPS: 52.0

Previous awards: 2018

Teruyoshi Kume, MD

(Kawasaki Medical School, Okayama)

Number of reviews: 10

RPS: 49.3

\section{Takahiro Okumura, MD}

(Nagoya University Graduate School of Medicine, Aichi)

Number of reviews: 8

RPS: 48.0

Previous awards: 2018

\section{Takahisa Kondo, MD}

(Nagoya University Graduate School of Medicine, Aichi) Number of reviews: 6

RPS: 46.0

\section{Takashi Kubo, MD}

(Wakayama Medical University, Wakayama)

Number of reviews: 11

RPS: 71.1

\section{Ken Kozuma, MD}

(Teikyo University, Tokyo)

Number of reviews: 11

RPS: 52.6

\section{Takashi Noda, MD}

(National Cerebral and Cardiovascular Center, Osaka)

Number of reviews: 10

RPS: 49.3

\section{Koichi Inoue, MD}

(Sakurabashi Watanabe Hospital, Osaka)

Number of reviews: 9

RPS: 49.1

Previous awards: 2015

\section{Yasuo Okumura, MD}

(Nihon University School of Medicine, Tokyo)

Number of reviews: 11

RPS: 46.4

\section{Shichiro Abe, MD}

(Dokkyo Medical University, Tochigi)

Number of reviews: 10

RPS: 45.6

\footnotetext{
*The Reviewer Performance Score (RPS) is determined as follows for reviewers who made at least 6 reviews in 2019 (review time limit, 14 days):

$* \mathbf{R P S}=[($ Number of reviews completed within 1 week $) \times 2+($ number of reviews completed within 2 weeks $) \times 1+($ number of reviews completed within 3 weeks $) \times 0.2] \times$ quality of review (average) $-($ number of declined reviews $)+($ number of editorial comments published in the Journal $) \times 10$.

The review quality of reviewers was evaluated for each manuscript by an Associate Editor who was in charge of the manuscript (range: 1 3) and the average score used.
}

The above Reviewers will be awarded by the Japanese Circulation Society with a Certificate of Achievement and an honorarium.

In the year ahead in 2020, we expect a steady increase in the number of submissions, as well as an increase in the scientific impact of the Journal. 